\title{
The Cooperation and Its Forms in Offenses Concerning with Narcotics Trafficking
}

\author{
Agron Bajri \\ European University of Tirana, Faculty of Justice, PhD Candidate \\ Email: agronbajri@gmail.com
}

\author{
Doi:10.5901/mjss.2015.v6n1s1p379
}

\begin{abstract}
The trafficking of narcotics is one of the images of the offenses with high social risk. These offenses have social threat not only about the character of the legal relations that affect them but also for the way the are committed, the category of persons who engage in these activities and the high level of cooperation between dangerous entities. The characteristic of these offenses is that they are considered committed under aggravated circumstances, when committed in collaboration or more than once. Almost all the figures of the offenses, such an element, is defined in a separate paragraph. This legal arrangement is made with the recent changes to the Penal Code, as the previous code predicted such circumstances just as aggravating circumstances that were used for the individualization of the punishment. Therefore, in this paper we will try to analyze these notions, for the importance that they present but also for the fact that they are the same for all types of these offenses. Viewed in this point of view, we will say that if the cultivation, production of narcotics; production and manufacture of narcotics and psychotropic substances; their import, export and transit ; marketing and distribution, (respectively the articles 284/c/2, 283/a, 283/a/2), are carried out in collaboration or more than once, considered committed in qualifying circumstances, and their sentence is higher.
\end{abstract}

Keywords: cooperation; forms of cooperation; narcotics trafficking;

\section{The Forms of Cooperation}

The cooperation of the persons in an offense can be of three types. In this way the penal legislation provides the simple cooperation ${ }^{1}$, according to article 25 of the Penal Code, the armed band ${ }^{2}$ and the criminal organization ${ }^{3}$ according to article 28 of the Penal Code, as more sophisticated forms of cooperation.

The commitment of penal acts by two or more persons, by agreement between them, is considered as a simple cooperation according to article 25 of the Penal Code.

Every situation of cooperation requires the fulfillment of elements, first the psychological element related to the subjective attitude and the operating element that is related with the objective attitude. The cooperation requires to each participant the psychological element, so that the act is committed with the consciousness of the assistance and participation of the others. Seen in this action definition it is not viewed simply as a part conducted and detached. Each of the collaborators is not called such if he becomes the protagonist of the operations independently, in which elements appear in the same offense. It will be considered complicit the case of any person who takes part in the criminal activity of the others by the simple will of entering to the group, bringing some kind of protection to them to facilitate the commission of illegal acts regarding the narcotics. As a case to be illustrated we mention here the person who carries another person in order to purchase the amount of the narcotic. In this way, offering with his trip, a conscious and independent contribution in the illegal activity of the transported person, the person making the transport will be criminally liable as a collaborator. But it should be noted that the person who takes measures to make the transport must necessarily know the purpose of transporting.

In selling narcotic substances the collaborator does not mean only the activity that comes from participating in the material execution of the crime, but also the action of preparation of the crime, placing at the disposal of the necessary tools and any kind of support of the specific case in the criminal activity of the author, to facilitate his work. To illustrate

\footnotetext{
${ }^{1}$ Article 25 of the penal code. Cooperation is called the criminal offense by two or more persons by agreement between them.

2. Article 28, paragraph 3 of the Penal Code. Armed gang is a special form of cooperation, which possessing weapons, military munitions and other necessary tools, aims the commission of offenses, provided in chapters V, VI and VII of the special section of this Code.

3. Article 28, paragraph 1 of the Penal Code. A criminal organization is the highest form of cooperation, in which are included three or more people and that is distinguished by a special degree of organization, structure, stability, duration, and the aim of committing one or more offenses, to realize material and non-material benefits.
} 
we mention the case of accompanying at the site of sale, hospitality in his residence for the exchange of the substance, the deposit of the psychotropic substance at home, the preservation of the money earned from narcotics etc. Thus, it is not definitely not required the author to be in physical contact with the narcotics. All the criminal activity is characterized by a flow of the criminal chain, where within this flow we find different positions or roles of the entities involved, which all together become part of the whole criminal activity. The collaborator in a criminal offense of a subject is called as such if he helps him waiting at home his friends, simplifies the keeping and concealment of the substance etc..

In such a case there are two elements of participation in the offense, first, that of the subjective the full consciousness to contribute in the conduct of the illegal activity and secondly that of the objective of linking his behavior with the criminal event 4 .

Depending on the concrete figure of the criminal offense, the cooperation can result in different forms and many different ways.

\section{The Simple Cooperation}

In the case of cultivation of narcotic plants will answer as a collaborator even the person that gives advice on how to plant, perform services and harvest the narcotic plants. In case of import of the narcotic and psychotropic drugs the customs authorities, that consciously allow their passage, will reply as an accomplice in the crime. In the case of laundering dirty money the tax authorities accept for granted an annual balance sheet of an economic entity, being aware that a portion of the revenue of this subject has come from criminal activities in connection with narcotics, will be responsible for this crime as an accomplice along with the specialist that develops the balance sheet and the person under whose authority is compiled this balance sheet. The cooperation divided into roles may be in range, assistant, promoter, organizer and the executor.

The simple cooperation can be achieved through a specific agreement on time or earlier and may be as a result of the agreement that is created impromptu or an the moment.

In the case of narcotic substances trafficking or other offenses related to narcotics, the most prevalent is that the cooperation is as a result of a previous agreement. According the forms of expression of will the agreement may be written, oral or with conclusive actions. In case the agreement is in writing it is easier to investigate the criminal case being that the acts committed by the subjects have left written traces. In cases when it is an instant agreement it should be considered the entirety of the elements whose analysis leads to the identification of the collaborators.

\section{The Cooperation as a Gang and Criminal Organization}

The cooperation that we mentioned above is its simplest form, the two most perfect forms and that present a higher social risk are: the armed gang and the criminal organizations. These, as special forms of cooperation, distinguished not only from the number of participants, but also on the degree of organization and stability in the performance of a large number of offenses. The criminal organization represents the highest degree of cooperation for conducting a stable criminal activity. According to Article 25/3 and 333 of the Penal Code, creating and participating in an armed gang or a criminal organization is punishable even if no criminal activity has begun. This is provided as such because of the high risk that these figures of offenses represent.

When the organizations commit the criminal offenses related to drugs their members will be divided into two categories:

1. The organizers, leaders and the funders of the criminal organization, who will be criminally liable under Article 284 / a of the Penal Code. ${ }^{5}$

2. All the other members, that shall be criminally liable under the concrete provision of the offense committed and article 333 of the Penal Code. ${ }^{6}$

This division made specifically under the criminal law is based on the importance of the offense committed, the extent of involvement of the subject in the offense committed and in the role that each of its subjects has during the performance.

The proof of creating a criminal organization that carries out offenses related to narcotics is a difficult process of inquiry.

4. The criminal offences in the field of narcotics. Pg. 118.

5. Article 284 / a of the the Penal Code. Organization and management of the criminal organizations.

6 . Article 333 of the penal code, Criminal organizations. 
They are very rare cases where magistrates ${ }^{7}$ may fall on their hands written documents that can prove this fact. The existence of a criminal organization simply cannot stand the fact that some people commit a criminal activity and several acts or isolated from each other. It should the existence of a series of episodes connected with each other, and the proof of the existence of structures, either organizational, technical or operational. These can be extracted in the confirmation of the preparation of the means and conditions to fulfill the criminal goals, from the reports among the collaborators, distribution of tasks, programming of a series of unspecified crimes, with the consciousness of each member participant in the criminal organization.

The component elements of the criminal organization consist of the formation and continuation of a social relationship between three or more persons, to realize a specified number of unlawful acts, as provided from the articles 283 to article 287 / a of the Penal Code.

This relation comes out from the following elements:

1. The existence of groups or a managing group.

2. The absolute supremacy of the group over the other collaborators, part of a hierarchical organization.

3. The existence of a common funding for performing all the operations with narcotics, with the obligation to jointly cope with the costs and potential losses.

4. The commitment of offenses with narcotics.

5. The existence of a stabilized report of the criminal organization with the illegal trafficking of narcotic substances, in a geographically best defined area.

The organization is called created from the moment that the members enter into an agreement and put the tools of any kind available to the criminal activity. For its formation is not sufficient just a simple disagreement, but the creation of a stable relationship, the result of the concrete actions and goals of the members. According to article $284 / \mathrm{a}$ and especially articles 333 and 334 of the code, it is not required to conduct a specific crime, provided by the articles 283 to 286/a, but must be confirmed a start of the activity of a criminal organization and its constituent structures.

The most prominent roles in the activity of a criminal organization are the organizer, the leader, the funder, the participant and the financial consultant.

The organizer is the person who coordinates the activities of members and ensures the functioning of the structures of the organization. He is the key figure and the highest authority, having the right to make the most important decisions for the organization. He maintains links with other organizations, carries out large purchases of psychotropic narcotic substances, deals with the corruption of state officials or structures makes decisions for the elimination of police officers or magistrate that violate "the collusion" by advancing in the investigation and detection of the organization.

The funder is the person who invests the capital in the criminal organization, aware of the criminal intent. This is an important role for the organization and also with very high social risk, since money is a necessary tool for conducting operations with narcotics. This is evidenced by the fact that, being an unlawful activity the exchange of drugs, is made by cash, but the last years the practice has proved that such an exchange can be made even with banking financial operations, since there are into play large amounts.

The leader is the person in the organization that carries out different functions including that from the routine operations, administrative, as well as other actions. His role we see divided in many ways, as enabling the new admissions, making decisions for the operation of the organization, manages the performance of all its daily operations, also makes sharing of tasks even of the other members. The concentration and specialization of the criminal organizations in certain sectors of their criminal activity as well as the large financial amounts that circulate make it necessary as a special picture of the organization, as an important subject, that of the financial consultant. Being that this activity is illegal, they need a reliable person to perform this task. The financial consultant is a central figure of the organization, who must have special professional-economic and organizational knowledge, that are performed all the financial specialized operations.

The participation in a criminal organization is a crime of the most simple form, which it does not require any special action, but simply accepting the entry into the organization. The actions which can perform a member are random depending on its purpose and needs.

In the investigation and trial of the criminal activity of an organization it is very important to individualise the criminal liability of any specific collaborator. For this reason the investigation organs must discover and prove the criminal activity of any of the members of the organization and not simply the fact of being in the criminal organization for which they are

7. Magistrates, are Prosecutors and Judges. 
accused. All the members of an organization in any of the ranks, by the subjective side act intentionally directly ${ }^{8}$ or indirectly ${ }^{9}$. Their intentional action consists not only in determining the awareness and willingness to give the contribution required by the criminal organization, but also in the consciousness to actively participate in all actions to implement the joint program. Also, it is sufficient the awareness that the personal activity is part of an organized structure without the need to know the identity of other members and having direct relations with them.

The will of participation in the organization is not necessarily shown with forms documented but are sufficient the conclusive acts, concrete actions, and that the mental element can be drawn even from performing of the typical acts by the other members of the organization. However the proof of the will of participation should be very precise and rigorous. To prove the mental element of the proceeding authority may not inquire into a person's psyche, except by examining of the objective elements emerged during the investigation and trial of the concrete case.

\section{The Investigation and Trial of the Criminal Offenses Related to Narcotics}

The criminal activity in relation to narcotics represents a very complex activity. These organizations to achieve their goal, and that consists in sending the case to the users, in order to realize profits, they need a very wide criminal structure to carry out the cultivation, production, manufacture, marketing and distribution of narcotic substances.

This is done by large criminal organizations, which have international extension. Only in the cultivation of the narcotic plants and distribution of narcotic and psychotropic drugs to the users participate a relatively large number of persons. This is because being an unlawful activity and not being carried out legally, these quite voluminous processes are realized through the introduction of a large number of people. Only in this way, this activity can be hidden as much as possible and the members of the criminal organizations stay, as far as possible away from police detection and investigation.

As in the other phases of this criminal activity, which are the production, manufacture, preparation, import, export, transit and trade of narcotic and psychotropic substances, carried out by a small number of international criminal organizations, with a lot of organization and very strict discipline, as well as equipped with numerous monetary and logistical means, which often do not possess even the state structures.

This makes it very hard to detect and capture the members of these organizations and the police or the other investigative organs, often are limited to the capture and conviction of the narcotic plant growers and the distributors of drugs to the users.

The investigation of these figures of offenses presents a series of specifications that relate to:

- The layout in time of the investigation,

This means the long and versatile investigation, being that the organization for which it is being investigated has a broad and possibly extended content to many countries. In addition, the organization conducts the criminal activity in certain periods of time, it needs adequate time to find the members, finding funding, finding and providing the narcotics, determining the moving channels etc. In this way a long extent of time of the investigation would lead to providing a broad picture of the activity that takes place, for the persons involved in this activity, and the role of each of them.

- $\quad$ The use of special methods for investigation.

Especially in these kind of figures of offenses it is necessary that the investigation _ developed is versatile, and using special methods of investigation. A great help would be to use the methods associated with the interception of the daily activity of the subjects either the phone tapping or field observations. On the other hand the infiltrated police officer would be a good method of investigation, without leaving unmentioned the stimulated purchase.

It is very important and the moment that relates to analyzing of the totality of the evidence obtained during the investigation phase as well as during the trial. This moment is translated into decision making of the competent body related to the goal setting of the role of each of the participants in the offense committed.

\section{Conclusions}

The criminal offenses relating to narcotic drugs are works with high social risk. For their good, full and on time investigation it is essential that the organs have the duty to deal with it, to have a working coordination between them.

8. The direct premeditation exists when a person foresees the consequences of the offense and wants their arrival. Penal Law (General Part) Shefqet Muçi, pg. 139.

9. The indirect premeditation exists when a person, even though he foresees but does not want the consequences, with consciousness allows their arrival. Penal Law (General Part) Shefqet Muçi, pg. 140. 
Despite the dangerousness of these offenses an organization and better coordination of the work between the organs dealing with the investigation, both domestically and internationally, would bring good high results in the terms of combating this criminal activity, in order to minimize or eliminate it.

The second paragraph of the article 284 / A provides criminal liability for the state employees that create facilities or favorable conditions for the criminal organizations. be hit.

This provision is made for the sole purpose that every part of the criminal chain related with these offenses should

The object of this offense are the legal relations established to ensure the legality of carrying out the state activities and to prevent the creation and functioning of criminal organizations. These facilities or conditions can be created as with active actions and with omissions. This type of criminal activity in specific cases can be transformed into part of the organization criminal activity. We will have to do with participation in a crime and not with his personal favoring, when the person in state functions, with knowledge of the activity of a criminal organization and drugs trafficking, is not limited to assist one or more of its members to avoid state investigations, but helps them with various information, with omissions according to the legal competencies, puts at the disposal of the organization logistics tools etc. favors the organization in complex in the implementation of its criminal activities and goals and thus gives a contribution from outside in the existence and continuity of the criminal organization.

According to the first paragraph of Article 284 / a subject of the criminal offense may be any person who has reached the age of criminal responsibility and is responsible in front of the law.

Whereas under the second paragraph we have to do with special subjects, persons with certain state functions that create conditions or the convenience for criminal organizations.

It is important to treat this criminal activity in the proper form, so that it does not become controlling of various social situations or for the worse to have broad impact on them.

A special importance should be given even to the preventive element in order to take concrete measures towards the preventive role.

Any kind of situation should be subject to specific analysis, becoming part of such analysis and cooperation with foreign organisms. These analyzes should serve not only for the treatment of concrete cases but also the prevention of criminal activity as a going concern.

Besides internal cooperation, the international cooperation is needed in order to ensure the proper commitment, in terms of taking concrete measures in order to implement the international agreements related to narcotic drugs.

\section{References}

Law No. 7975 dated 26.05.1995 "On narcotic drugs and psychotropic substances".

The Penal Code of the Republic of Albania.

Unifying Decision of the Supreme Court dated 27.03.2008

Begeja. S. (1998)The scientific basis of the organization and planning of the investigation of criminal offenses "Tirana -

The Penal Procedure Code of the Republic of Albania

Muçi. Sh. (2012)Penal Law (General Part), Publisher Botimet Dudaj. 